\title{
“Pengaruh Adversity Quotient Terhadap Kinerja Karyawan Melalui Motivasi Kerja Sebagai Variabel Intervening ("Studi Pada Pengemudi Taksi Konvensional di Kota Medan)"
}

\author{
Anggia Sari Lubis \\ Fakultas Ekonomi Universitas Muslim Nusantara AL-Wasliyah, Medan \\ Sari Wulandari \\ Fakultas Ekonomi Universitas Muslim Nusantara AL-Wasliyah, Medan \\ *Corresponding author: E-mail: anggiasarilubis@gmail.com,wulanda.21@gmail.com
}

\begin{abstract}
Abstrak
Tujuan dari penelitian ini adalah untuk mengukur seberapa besar pengaruh adversity quotient terhadap kinerja karyawan melalui motivasi kerja sebagai variabel intervening studi pada pengemudi taksi konvensional di Kota Medan. Sifat dari penelitian ini adalah asosiatif dan jenis penelitian adalah deskriptif kuantitatif. Sampel penelitian ini adalah 253 orang pengemudi taksi konvensional di Kota Medan. Data yang telah dikumpulkan melalui kuesioner yang sudah valid dan reliabel, kemudian diolah menggunakan pendekatan Path analysis. Berdasarkan hasil penelitian, diketahui bahwa hasil penelitian ini adalah (1) Adversity quotient berpengaruh positif dan signifikan terhadap kinerja pegawai, (2) Adversity quotient berpengaruh positif dan signifikan terhadap motivasi kerja, (3) Motivasi kerja berpengaruh positif dan signifikan terhadap kinerja pengemudi taksi konvensional, (4) Motivasi kerja sebagai mediasi yang sempurna antara adversity quotient dan kinerja pengemudi taksi konvensional.
\end{abstract}

Kata Kunci: Adversity Quotient, Motivasi Kerja, Kinerja

\section{Abstract}

The purpose of this study is to analyze and determine the effect of adversity quotient on Employee Peformance Through Job Motivation as an intervening variable in the conventional taxi driver in Medan. The nature of this study was associative,and the type of this research was quantitative. A sample of this research are 253 conventional taxi driver in Medan. The data that has been collected through a valid and reliable questionnaire, then processed using Path analysis approach. Results of this study are (1) adversity quotient has positive effect and significant effect on the employee performance, (2) adversity quotient has positive and significant effect on job motivation, (3) Job motivation has a positive and significant effect on the employee performance, (4) Job motivation as a perfect mediation between adversity quotient and employee performance. 


\section{PENDAHULUAN}

\section{Latar Belakang Masalah}

Persaingan diantara taksi konvensional dengan taksi berbasis aplikasi online semakin meningkat. Dengan hadirnya taksi berbasis aplikasi online, posisi taksi konvensional semakin terpojok. Banyak penumpang yang pada awalnya menggunakan jasa taksi konvensional beralih ke taksi berbasis aplikasi online. Faktor utama yang menyebabkan berpindahnya penumpang kepada taksi berbasis aplikasi online adalah dikarenakan adanya perbedaan tarif yang cukup signifikan. Berdasarkan pengamatan peneliti, seorang penumpang taksi berbasis aplikasi online hanya perlu membayar Rp.39.000,- untuk jarak tempuh 9km, dibandingkan jika penumpang menggunakan jasa taksi konvensional dengan jarak tempuh yang sama tetapi dengan biaya Rp. 64.000,-. Selain dari perbedaan tarif yang cukup signifikan, para penumpang taksi berbasis aplikasi online juga diberikan kemudahan dalam proses pemesanan taksi, dengan menggunakan aplikasi pada smartphone para penumpang dapat dengan mudah memesan taksi, dan hanya dalam waktu tunggu beberapa menit, calon penumpang sudah dijemput oleh taksi berbasis aplikasi online. Jika pada satu sisi terdapat pihak yang sangat diuntungkan dengan kondisi ini yaitu para penumpang dan pengemudi taksi berbasis aplikasi online, tetapi ada pula pihak yang dirugikan yaitu perusahaan taksi konvensional terutama para pengemudi taksi konvensional. Dengan adanya gempuran persaingan dari taksi berbasis aplikasi online otomatis terjadi pengurangan jumlah penumpang yang berakibat pada pengurangan pendapatan pengemudi taksi.

Dengan adanya keadaan seperti yang dipaparkan pada paragraf sebelumnya, dapat mengakibatkan penurunan kinerja pengemudi taksi konvensional. Padahal jika kinerja yang dicapai para pengemudi taksi konvensional baik, pada akhirnya akan memberikan kontribusi terhadap kinerja perusahaan. Keberhasilan perusahaan dalam memperbaiki kinerja perusahaan sangat tergantung pada kualitas sumber daya manusia yang bersangkutan dalam bekerja. Kinerja merupakan hasil kerja yang dapat dicapai oleh seseorang atau sekelompok orang dalam suatu organisasi baik secara kuantitatif maupun kualitatif (Mathis dan Jackson, 2006). Setiap kegiatan yang dilakukan oleh seseorang didorong oleh suatu kekuasaan dalam diri orang tersebut, kekuatan pendorong inilah yang disebut motivasi.

Motivasi kerja karyawan dalam suatu organisasi dapat dianggap sederhana dan dapat pula menjadi masalah yang kompleks, karena pada dasarnya manusia mudah untuk dimotivasi dengan memberikan apa yang menjadi keinginannya. Ada tiga elemen kunci dalam motivasi yaitu upaya, tujuan organisasi dan kebutuhan. Pada umumnya kinerja yang tinggi selalu dihubungkan dengan motivasi kerja yang tinggi pula. Jika dihubungkan dengan keadaan pengemudi taksi konvensional saat ini, maka tidak heran bahwa terjadi penurunan kinerja dikarenakan adanya oleh keadaan sulit yang dihadapi oleh para pengemudi taksi konvensional. Untuk mendorong peningkatan kinerja para pengemudi taksi konvensional, dibutuhkan keyakinan diri akan kemampuan untuk mengatasi rintangan-rintangan dalam menjalankan usaha yang dalam hal ini merupakan konsep adversity quotient (Stoltz,2000). Adversity quotient merupakan bentuk kecerdasan yang melatar belakangi kesuksesan seseorang dalam menghadapi tantangan disaat terjadi kesulitan. Jika seseorang memiliki kualitas adversity quotient yang baik maka akan mampu mengatasi rintangan yang menghalangi seseorang dalam mencapai tujuannya. Tanpa adanya adversity quotient yang baik maka dikhawatirkan para pengemudi taksi akan mengalami frustasi dan kegamangan dalam menjalani pekerjaannya sehari-hari .

Objek dari penelitian ini adalah para pengemudi taksi konvensional di Kota Medan. Tidak kurang dari 824 pengemudi taksi konvensional dari berbagai perusahaan taksi 
konvensional yang masih aktif yang berada di Kota Medan . Berdasarkan latar belakang diatas, maka penelitian ini dimaksudkan untuk mengetahui bagaimana "Pengaruh adversity quotient terhadap kinerja karyawan melalui motivasi kerja sebagai variabel intervening (Studi Pada Para Pengemudi Taksi Konvensional di Kota Medan)".

\section{A. Rumusan Masalah}

Berdasarkan uraian pada latar belakang diatas Maka permasalahan yang akan diteliti adalah:

1. Adakah pengaruh adversity quotient terhadap Kinerja para pengemudi taksi konvensional di Kota Medan?

2. Adakah pengaruh adversity quotient terhadap Motivasi kerja pengemudi taksi konvensional di Kota Medan?

3. Adakah pengaruh motivasi kerja terhadap kinerja pengemudi taksi konvensional di Kota Medan?

4. Apakah motivasi kerja dapat memediasi sempurna antara adversity quotient dan kinerja pengemudi taksi konvensional di Kota Medan?

B. Tujuan Penelitian

Secara khusus penelitian ini bertujuan untuk:

1. Untuk mengetahui adakah pengaruh adversity quotient terhadap kinerja para pengemudi taksi konvensional di Kota Medan?

2. Untuk mengetahui adakah pengaruh adversity quotient terhadap Motivasi kerja pengemudi taksi konvensional di Kota Medan?

3. Untuk mengetahui adakah pengaruh motivasi kerja terhadap kinerja pengemudi taksi konvensional di Kota Medan?

4. Untuk mengetahui apakah motivasi kerja dapat memediasi sempurna antara adversity quotient dan kinerja pengemudi taksi konvensional di Kota Medan?

\section{Manfaat Penelitian}

Penelitian ini diharapkan dapat memberikan manfaat sebagai berikut:
1. Bagi Peneliti, Penelitian ini diharapkan dapat memperluas wawasan peneliti, sehingga peneliti mengetahui apa-apa saja variabel indikator yang memberikan pengaruh bagi kinerja karyawan

2. Bagi Perusahaan, Penelitian ini diharapkan dapat memberikan manfaaat bagi perusahaan, baik sebagai bahan pertimbangan ataupun sebagai evaluasi atas kinerja karyawan adversity quotient dan motivasi kerja.

\section{METODE PENELITIAN}

\section{A. Bentuk Penelitian}

Bentuk penelitian yang digunakan dalam penelitian ini adalah bentuk penelitian deskriptif, dengan jenis penelitian kuantitatif. Sedangkan sifat penelitian ini adalah penelitian asosiatif yaitu penelitian yang menghubungkan dua variabel atau lebih.

\section{B. Tempat Dan Waktu Penelitian}

Penelitian ini dilakukan Tempat penelitian dilakukan di pangkalan Armada Taksi di Kota Medan. Waktu kegiatan penelitian dimulai bulan Oktober 2017- Maret 2018.

\section{Populasi dan Sampel}

Subjek penelitian dalam penelitian ini adalah populasi, populasi merupakan keseluruhan unit atau individu dalam ruang lingkup yang ingin diteliti, populasi dibatasi sebagai jumlah penduduk atau jumlah individu yang paling sedikit memiliki satu sifat yang sama. Oleh karena itu populasi yang diambil adalah seluruh pengemudi Taksi Konvensional di Kota Medan yang berjumlah 824 orang. Metode penentuan banyaknya sampel dilakukan dengan menggunakan Tabel Krecjie\&Morgan dalam (Sekaran, 2009) yaitu dengan jumlah populasi diatas 800 orang, maka sampel ditentukan sebanyak 253 orang. Teknik penarikan sampel dalam penelitian ini menggunakan teknik nonprobability sampling yaitu dengan metode convenience sampling. Convenience sampling yaitu metode pengambilan sampel dilakukan hanya atas dasar pertimbangan kemudahan. Seseorang 
dijadikan sampel atas dasar kesediaan mereka dalam mengisi kuesioner.

\section{Jenis Dan Sumber Data}

Jenis dan sumber data dalam penelitian ini menggunakan teknik pengumpulan data primer dan pengumpulan data sekunder. Pengumpulan data primer dilakukan dengan menyebarkan angket/kuesioner yang sudah melewati tahap pengujian valliditas dan reliabilitas bagi responden penelitian, sedangkan pengumpulan data sekunder di lakukan dengan metode wawancara observasi dan studi kepustakaan dan studi dokumentasi untuk mendukung data primer.

\section{E. Teknik Analisis Data}

1. Uji Asumsi Klasik

Gambar 1. Model Jalur Penelitian
Uji asumsi klasik diperlukan untuk dapat melakukan analisis regresi berganda Pengujian tersebut dilakukan untuk menghindari atau mengurangi bias atas hasil penelitian yang diperoleh. Pengujian asumsi klasik yang digunakan dalam penelitian ini meliputi uji normalitas, uji multikolinearitas, uji heteroskedastisitas dan uji autokorelasi (Erlina, 2011)

2. Analisis Jalur (Path Analysis) menurut Sugiyono (2007) merupakan pengembangan dari analisis regresi linier, sehingga analisis regresi dapat dikatakan sebagai bentuk khusus dari analisis jalur (regression is special case of path analysis). Model jalur penelitian ini adalah sebagai berikut :

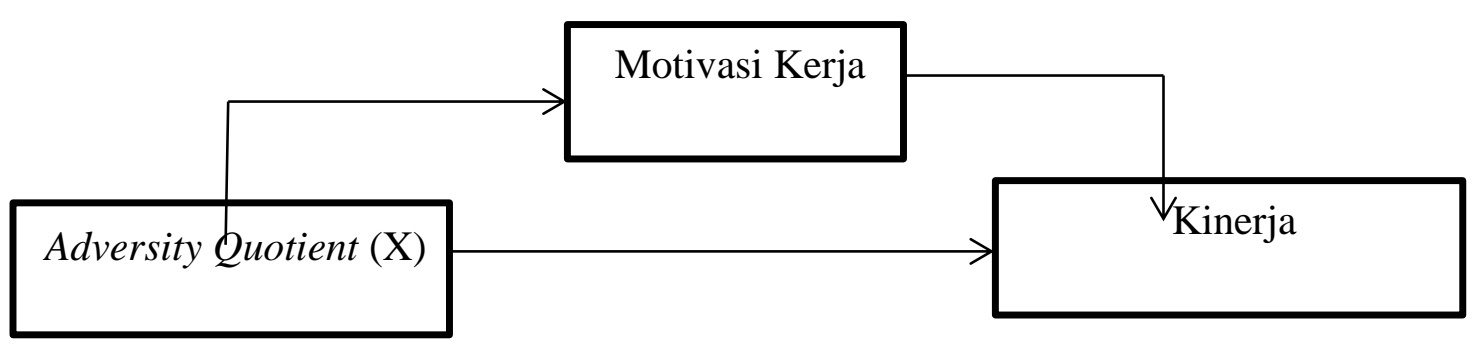

Ada dua variabel tak bebas dalam model yaitu Y dan Z. Sebagai konsekuensinya diperoleh dua persamaan tergantung yaitu persamaan 1 yang menunjukkan hubungan Motivasi Kerja menyeluruh $(\mathrm{Y})$ dengan satu vari1abel $(\mathrm{X})$, dan yang kedua persamaan dua yang menunjukkan hubungan kinerja (Z) dengan dua variabel ( $\mathrm{X}$ dan $\mathrm{Y}$ ).

Persamaan Regresi :

$\mathrm{Y}=\mathrm{a}+\mathrm{bX}$

$\mathrm{Z}=\mathrm{a}+\mathrm{bX}+\mathrm{bY}$

Keterangan :

$\mathrm{Y}=$ variable dependent (Motivasi)

$\mathrm{Z}=$ variable dependent (Kinerja Pengemudi

Taksi Konvensional)

$\mathrm{b}=$ koefisien regresi adversity quotient

$\mathrm{X}=$ variabel independent (adversity quotient)

$\mathrm{e}=$ faktor di luar Pengaruh yang ditimbulkan

dari model jalur di atas dapat ditulis sebagai berikut :

a. Pengaruh Langsung (Direct Effect atau DE) i. Pengaruh variabel adversity quotient terhadap kinerja

$\mathrm{X} 1 \longrightarrow \mathrm{Z}=\rho \mathrm{Zx}$

ii. Pengaruh variabel adversity quotient terhadap motivasi

$\mathrm{X} \longrightarrow \mathrm{x}=\rho \mathrm{x}$

iii. Pengaruh motivasi kerja terhadap kinerja

Y $\mathrm{Z}=\rho \mathrm{Yz}$

b. Pengaruh Tidak Langsung (Indirect Effect atau IE)

i. Pengaruh variabel adversity quotient terhadap kinerja melalui motivasi kerja

$$
\mathrm{X} 1 \longrightarrow \mathrm{Z} \longrightarrow(\rho \mathrm{Zx}) \mathrm{x}(\rho \mathrm{Zy})
$$

c. Pengaruh Total (Total Effect)

i. Pengaruh variabel adversity quotient terhadap kinerja melalui motivasi kerja $\mathrm{X} 1 \longrightarrow \mathrm{X} 1 \longrightarrow 2=\rho \mathrm{Zx}+(\rho \mathrm{Zx}) \mathrm{x}(\rho \mathrm{Zx})$

3. Koefisien Determinasi 
Koefisien determinasi $\left(\mathrm{R}^{2}\right)$ pada intinya mengukur seberapa jauh kemampuan model dalam menerangkan variasi variabel dependen. Nilai koefisien determinasi adalah antara nol (0) dan satu (1). Nilai $\mathrm{R}^{2}$ yang kecil berarti kemampuan variabel-variabel independen (bebas) dalam menjelaskan variasi variabel dependen amat terbatas. Nilai yang mendekati satu berarti variabel-variabel independen memberikan hampir semua informasi yang dibutuhkan untuk memprediksi variasi variabel dependen (Ghozali, 2016)

\section{F. Kerangka Berpikir}

Adversity Quotient adalah kemampuan seseorang untuk mengubah hambatan atau kesulitan menjadi suatu peluang keberhasilan dalam mencapai tujuan melalui kemampuan berpikir, mengelola dan mengarahkan tindakan yang membentuk suatu pola-pola tanggapan kognitif dan perilaku atas peristiwa-peristiwa dalam tantangan yang dihadapi. Control, origin, reach dan endurance adalah indikator yang diukur dalam penelitian ini. Kinerja Karyawan adalah hasil kerja secara kualitas dan kuantitas yang dicapai oleh seseorang karyawan dalam melaksanakan tugasnya sesuai dengan tanggung jawab yang diberikan kepada karyawan tersebut. Indikator penelitian untuk kineerja terdiri dari kuantitas, kualitas, ketepatan waktu, kehadiran, serta kemampuan untuk bekerja sama. Motivasi
Kerja menurut Umar (2013) adalah dorongan dan keinginan yang ada di dalam diri manusia untuk melaksanakan tugas-tugas pekerjaannya dengan baik .Indikator motivasi kerja diukur dengan hubungan dengan rekan kerja dan atasan, lingkungan kerja, kesempatan meningkatkan pengetahuan dan keterampilan, dan pemberian tunjangan.

\section{G.Hipotesis Penelitian}

1. Ada pengaruh positif dan signifikan antara adversity quotient terhadap kinerja para pengemudi taksi konvensional di Kota Medan.

2. Ada pengaruh positif dan signifikan antara adversity quotient terhadap motivasi kerja para pengemudi taksi konvensional di Kota Medan.

3. Ada pengaruh positif motivasi kerja terhadap kinerja para pengemudi taksi konvensional di Kota Medan.

4. Motivasi kerja dapat memediasi sempurna antara adversity quotient dan kinerja para pengemudi taksi konvensional di Kota Medan.

\section{HASIL PENELITIAN DAN PEMBAHASAN}

\section{A. HASIL UJI ASUMSI KLASIK}

1. Hasil Uji Normalitas Persamaan $Y=a+$ bX

Uji untuk mengetahui apakah data berdistribusi normal atau mendekati normal dilakukan dengan pengujian KolmogorovSmirnov test. Hasil pengujian dapat dilihat pada Tabel 3.1 berikut ini:

Tabel 3.1. Hasil Uji Normalitas

One-Sample Kolmogorov-Smirnov Test

\begin{tabular}{|ll|r|}
\hline & & $\begin{array}{c}\text { Unstandardiz } \\
\text { ed Residual }\end{array}$ \\
\hline N & Mean & 253 \\
Normal Parameters ${ }^{\mathrm{a}, \mathrm{b}}$ &, 0000000 \\
& Std. Deviation & 2,07688879 \\
Most Extreme & Absolute &, 102 \\
Differences & Positive &, 102 \\
& Negative &,- 086 \\
Test Statistic & &, 432 \\
Asymp. Sig. (2-tailed) & &, $229 \mathrm{c}$ \\
\hline
\end{tabular}

Berdasarkan Tabel 3.1 diketahui bahwa nilai Kolmogorov-Smirnov test sebesar 0.432 dan asymp. Sig (2-tailed) sebesar 0,229 lebih besar dari 0,05. Dengan demikian maka 
model regresi hipotesis tersebut memenuhi asumsi normalitas.

\section{Uji Multikolinieritas Persamaan $\mathrm{Y}=\mathrm{a}+$ bX}

Uji untuk menginformasikan terjadinya hubungan antara variabel-variabel bebas dan hubungan yang terjadi cukup besar, hasil pengujian dapat dilihat pada Tabel 3.2 berikut ini:

Hasil uji multikolinearitas dalam penelitian ini adalah:

\section{Tabel 3.2}

X $\quad Y$

$\begin{array}{lll}X & 1.000000 & 0.317905 \\ Y & 0.317905 & 1.000000\end{array}$

Berdasarkan pada hasil output matrik korelasi di atas, korelasi X dengan $\mathrm{Y}$ adalah 0.317905, tidak terdapat korelasi antar variabel independen yang diatas 0.90. Jadi dapat disimpulkan bahwa tidak terdapat multikolinearitas antar variabel independen. Cara kedua untuk mendeteksi ada atau tidaknya multikolinearitas adalah dengan menghitung nilai Variance Inflation Factor (VIF), nilai VIF dalam penelitian ini adalah sebagai berikut:

Tabel 3.3

Variance Inflation Factors

Date: 04/03/18 Time: 12:53

Sample: 1253

Included observations: 253

\begin{tabular}{|c|c|c|c|}
\hline Variable & $\begin{array}{l}\text { Coefficient } \\
\text { Variance }\end{array}$ & $\begin{array}{c}\text { Uncentered } \\
\text { VIF }\end{array}$ & $\begin{array}{c}\text { Centered } \\
\text { VIF }\end{array}$ \\
\hline $\mathrm{C}$ & 10.63457 & 120.3523 & NA \\
\hline$X$ & 0.014632 & 154.5400 & 1.602630 \\
\hline Y & 0.026928 & 164.6760 & 2.906743 \\
\hline
\end{tabular}

Nilai centered VIF untuk ketiga variabel tidak ada yang diatas 10 , sehingga dengan demikian terbukti tidak ada permasalahan multikolinearitas.

\section{Uji Heteroskedastisitas Persamaan $\mathrm{Y}=$ $\mathbf{a}+\mathbf{b X}$}

Untuk menguji apakah dalam model regresi terjadi ketidaksamaan variance dari residual satu pengamatan ke pengamatan yang lain, hasil pengujian dapat dilihat pada Tabel 3.4 berikut ini:

Tabel 3.4

Heteroskedasticity Test: Glejser

\begin{tabular}{llll}
\hline \hline F-statistic & 0.689779 & Prob. F(3,96) & 0.5605 \\
Obs*R-squared & 2.110074 & Prob. Chi-Square(3) & 0.5499 \\
Scaled explained SS & 2.396111 & Prob. Chi-Square(3) & 0.4944 \\
\hline \hline
\end{tabular}

Test Equation:

Dependent Variable: ARESID

Method: Least Squares

Date: 04/03/18 Time: 11:49

Sample: 1253

Included observations: 253 


\begin{tabular}{lrlll}
\hline \hline \multicolumn{1}{c}{ Variable } & Coefficient & Std. Error & t-Statistic & Prob. \\
\hline \hline \multicolumn{1}{c}{ C } & 4.509907 & 2.115332 & 2.132009 & 0.0356 \\
X & 0.007217 & 0.078465 & 0.091983 & 0.9269 \\
Y & -0.053004 & 0.106443 & -0.497957 & 0.6197 \\
\hline \hline & & & \\
R-squared & 0.021101 & Mean dependent var & 2.199224 \\
Adjusted R-squared & -0.009490 & S.D. dependent var & 1.919112 \\
S.E. of regression & 1.928196 & Akaike info criterion & 4.190225 \\
Sum squared resid & 356.9224 & Schwarz criterion & 4.294432 \\
Log likelihood & -205.5113 & Hannan-Quinn criter. & 4.232400 \\
F-statistic & 0.689779 & Durbin-Watson stat & 2.231434 \\
Prob(F-statistic) & 0.560467 & & & \\
\hline \hline
\end{tabular}

Hasil tampilan output diatas menunjukkan bahwa Terima Ho yaitu terjadi homokedastisitas karena nilai Prob F sebesar 0.5605 lebih besar dari 0.05. Yang berarti bahwa tidak terjadi heteroskedastitisas.

\section{Hasil Uji Normalitas Persamaan $Y=a+$ bX+bY}

Uji untuk mengetahui apakah data berdistribusi normal atau mendekati normal dilakukan dengan pengujian Kolmogorov-Smirnov test . Hasil pengujian dapat dilihat pada Tabel 3.1 berikut ini:

Tabel 3.5. Hasil Uji Normalitas

One-Sample Kolmogorov-Smirnov Test

\begin{tabular}{|ll|r|}
\hline & & $\begin{array}{r}\text { Unstandardiz } \\
\text { ed Residual }\end{array}$ \\
\hline N & & 253 \\
Normal Parameters ${ }^{\mathrm{a}, \mathrm{b}}$ & Mean &, 0000000 \\
& Std. Deviation & 2,07688879 \\
Most Extreme & Absolute &, 102 \\
Differences & Positive &, 102 \\
& Negative &,- 086 \\
Test Statistic & &, 519 \\
Asymp. Sig. (2-tailed) & &, $318^{\mathrm{c}}$ \\
\hline
\end{tabular}

a. Test distribution is Normal

b. Calculated from data

Sumber: Hasil Penelitian, 2018 (Data Diolah)

Berdasarkan Tabel 3.1 diketahui bahwa nilai Kolmogorov-Smirnov test sebesar 0.519 dan asymp. Sig (2-tailed) sebesar 0,318 lebih besar dari 0,05. Dengan demikian maka model regresi hipotesis tersebut memenuhi asumsi normalitas.

\section{Uji Multikolinieritas Persamaan $\mathrm{Y}=\mathbf{a}+$ bX + bY}

Uji untuk menginformasikan terjadinya hubungan antara variabel-variabel bebas dan hubungan yang terjadi cukup besar, hasil pengujian dapat dilihat pada Tabel 3.2 berikut ini: 
Hasil uji multikolinearitas dalam penelitian ini adalah:

Tabel 3.6

\begin{tabular}{cccc} 
& $\mathrm{X}$ & $\mathrm{Y}$ & $\mathrm{Z}$ \\
\hline \hline $\mathrm{X}$ & 1.000000 & 0.227908 & 0.341572 \\
$\mathrm{Y}$ & 0.227908 & 1.000000 & 0.487953 \\
$\mathrm{Z}$ & 0.341572 & 0.487953 & 1.000000
\end{tabular}

Berdasarkan pada hasil output matrik korelasi di atas, korelasi $\mathrm{X}$ dengan $\mathrm{Y}$ adalah 0.227908 , korelasi antara $\mathrm{X}$ dengan $\mathrm{Z}$ adalah 0.341572 dan korelasi antara $\mathrm{Y}$ dan $\mathrm{Z}$ adalah sebesar 0.487953 . Tidak terdapat korelasi antar variabel independen yang diatas 0.90. Jadi dapat disimpulkan bahwa tidak terdapat multikolinearitas antar variabel independen.

Cara kedua untuk mendeteksi ada atau tidaknya multikolinearitas adalah dengan menghitung nilai Variance Inflation Factor (VIF), nilai VIF dalam penelitian ini adalah sebagai berikut:

Tabel 3.7

Variance Inflation Factors

Date: 04/03/18 Time: 12:53

Sample: 1253

Included observations: 253

\begin{tabular}{|c|c|c|c|}
\hline Variable & $\begin{array}{l}\text { Coefficient } \\
\text { Variance }\end{array}$ & $\begin{array}{c}\text { Uncentered } \\
\text { VIF }\end{array}$ & $\begin{array}{l}\text { Centered } \\
\text { VIF }\end{array}$ \\
\hline $\mathrm{C}$ & 10.23452 & 110.3523 & NA \\
\hline$X$ & 0.016634 & 114.5400 & 1302560 \\
\hline Y & 0.036925 & 134.6760 & 2.706443 \\
\hline Z & 0.040692 & 216.6709 & 3.770826 \\
\hline
\end{tabular}

Nilai centered VIF untuk ketiga variabel tidak ada yang diatas 10 , sehingga dengan demikian terbukti tidak ada permasalahan multikolinearitas.

\section{Uji Heteroskedastisitas Persamaan $Y=$ $\mathbf{a}+\mathbf{b X}+\mathbf{b Y}$}

Untuk menguji apakah dalam model regresi terjadi ketidaksamaan variance dari residual satu pengamatan ke pengamatan yang lain, hasil pengujian dapat dilihat pada Tabel $\quad 3.8 \quad$ berikut ini:

Tabel 3.8

Heteroskedasticity Test: Glejser

\begin{tabular}{llll}
\hline \hline F-statistic & 0.689779 & Prob. F(3,96) & 0.4605 \\
Obs*R-squared & 2.110074 & Prob. Chi-Square(3) & 0.4499 \\
Scaled explained SS & 2.396111 & Prob. Chi-Square(3) & 0.3944 \\
\hline \hline
\end{tabular}

Test Equation:

Dependent Variable: ARESID

Method: Least Squares 
Included observations: 253

\begin{tabular}{lrlll}
\hline \hline \multicolumn{1}{c}{ Variable } & Coefficient & Std. Error & t-Statistic & Prob. \\
\hline \hline C & 4.509907 & 2.115332 & 2.132009 & 0.0256 \\
X & 0.007217 & 0.078465 & 0.091983 & 0.7269 \\
Y & -0.033004 & 0.106443 & -0.497957 & 0.5197 \\
Z & -0.074208 & 0.093308 & -0.366616 & 0.6147 \\
\hline \hline & & & \\
R-squared & 0.031101 & Mean dependent var & 2.179224 \\
Adjusted R-squared & -0.008490 & S.D. dependent var & 1.939112 \\
S.E. of regression & 1.828196 & Akaike info criterion & 4.170225 \\
Sum squared resid & 346.9224 & Schwarz criterion & 4.254432 \\
Log likelihood & -215.5113 & Hannan-Quinn criter. & 4.262400 \\
F-statistic & 0.589779 & Durbin-Watson stat & 2.291434 \\
Prob(F-statistic) & 0.460467 & & \\
\hline \hline
\end{tabular}

Hasil tampilan output diatas menunjukkan bahwa Terima Ho yaitu terjadi homokedastisitas karena nilai Prob F sebesar 0.4605 lebih besar dari 0.05. Yang berarti bahwa tidak terjadi heteroskedastitisas.

\section{B. Hasil Uji Regresi dan PATH Analysis}

1. Hasil pengujian regresi untuk persamaan 1: $\quad \mathrm{Y}=\mathrm{a}+\mathrm{bX}$ dengan menggunakan software Eviews 10 adalah sebagai berikut:

Tabel 3.9

Dependent Variable: $Y$

Method: Least Squares

Date: 03/06/18 Time: 09:26

Sample: 1253

Included observations: 253

\begin{tabular}{lrlll}
\hline \hline \multicolumn{1}{c}{ Variable } & Coefficient & Std. Error & t-Statistic & Prob. \\
\hline \hline C & 19.46397 & 3.261068 & 5.968588 & 0.0000 \\
X & 0.298940 & 0.120965 & 2.471302 & 0.0152 \\
Y & 0.359291 & 0.143847 & 2.497728 & 0.0142 \\
\hline \hline R-squared & 0.512629 & Mean dependent var & 50.43000 \\
Adjusted R-squared & 0.497398 & S.D. dependent var & 4.192959 \\
S.E. of regression & 2.972574 & Akaike info criterion & 5.055912 \\
Sum squared resid & 848.2748 & Schwarz criterion & 5.160118 \\
Log likelihood & -248.7956 & Hannan-Quinn criter. & 5.098086 \\
F-statistic & 33.65834 & Durbin-Watson stat & 1.950645 \\
Prob(F-statistic) & 0.000000 & & & \\
\hline \hline
\end{tabular}

a

\section{. Koefisien Determinasi}

Tampilan output Eviews diatas menunjukkan besarnya Adjusted R Squared adalah sebesar 0.497398, hal ini berarti bahwa $49.7 \%$ variasi motivasi kerja (Y) dapat dijelaskan oleh adversity quotient 
sedangkan sisanya 51,3\% dijelaskan oleh variabel-variabel lain diluar model penelitian ini.

\section{b. Uji Signifikansi Parameter Individual} (Uji Statistik t)

Variabel independen yang dimasukkan ke dalam model adalah signifikan, hal ini terlihat dari nilai probabilitas signifikansi ketiganya dibawah 0.05. Uji $\mathrm{t}$ digunakan untuk mengetahui apakah variabel independen secara parsial berpengaruh terhadap variabel dependen. Kriteria pengambilan keputusan untuk uji statistik $\mathrm{t}$, yaitu apabila $\mathrm{t}$ hitung $>\mathrm{t}$ tabel atau sig $<\alpha=5 \%$, maka H1 diterima atau apabila $\mathrm{t}$ hitung, $\mathrm{t}$ tabel atau sig $>\alpha=5 \%$, maka $\mathrm{H} 1$ tidak dapat diterima. Berdasarkan hasil perhitungan statistik seperti pada Tabel 3.9, maka diperoleh persamaan regresi linear

berganda sebagai berikut:

$$
Y=19,464+0,299 X 1
$$

\section{Konstanta}

Berdasarkan Tabel 3.9 dan persamaan tersebut dapat diketahui bahwa konstanta $(\alpha)$ mempunyai koefisien regresi sebesar 19,464 artinya jika variabel adversity quotient (X) dianggap nol, maka adanya kenaikan kinerja sebesar 194,64 \% pada pengemudi taksi konvensional di kota Medan.

\section{Adversity Quotient}

Variabel adversity quotient (AQ) memiliki koefisien regresi sebesar 0,299 , artinya setiap kenaikan variabel AQ sebesar 1\%,maka akan terjadi peningkatan kinerja sebesar $29,9 \%$ dengan asumsi variabel lain dianggap konstan. Signifikansi variabel AQ sebesar $0,0152<\alpha=5 \%$. Maka secara parsial AQ berpengaruh signifikan terhadap motivasi kerja pengemudi taksi konvensional di Kota Medan.

2. Hasil pengujian regresi untuk persamaan 2: $\mathrm{Z}=\mathrm{bX}+\mathrm{bY}$ dengan menggunakan software Eviews 10 adalah sebagai berikut:

Tabel 3.10

Dependent Variable: Z

Method: Least Squares

Date: 04/03/18 Time: 09:06

Sample: 1253

Included observations: 253

\begin{tabular}{lrlll}
\hline \hline \multicolumn{1}{c}{ Variable } & Coefficient & Std. Error & t-Statistic & Prob. \\
\hline \hline C & 16.46117 & 2.861068 & 4.965488 & 0.0000 \\
X & 0.321788 & 0.187965 & 2.371652 & 0.0002 \\
Y & 0.430099 & 0.153096 & 2.341606 & 0.0129 \\
Z & 0.439281 & 0.167847 & 2.487728 & 0.0072 \\
\hline \hline R-squared & 0.415629 & Mean dependent var & 50.63000 \\
Adjusted R-squared & 0.387398 & S.D. dependent var & 4.142959 \\
S.E. of regression & 2.965574 & Akaike info criterion & 5.055912 \\
Sum squared resid & 848.7648 & Schwarz criterion & 5.190118 \\
Log likelihood & -248.6956 & Hannan-Quinn criter. & 5.888086 \\
F-statistic & 30.55834 & Durbin-Watson stat & 1.850645 \\
Prob(F-statistic) & 0.000000 & & & \\
\hline \hline
\end{tabular}

a. 


\section{Koefisien Determinasi}

Tampilan output Eviews diatas menunjukkan besarnya Adjusted R Squared adalah sebesar 0.387398, hal ini berarti bahwa $38.7 \%$ variasi Kinerja karyawan (Z) dapat dijelaskan oleh variasi dari dua variabel independent yang terdiri dari adversity quotient, dan motivasi kerja sedangkan sisanya $61,3 \%$ dijelaskan oleh variabel-variabel lain diluar model penelitian ini.

\section{b. Uji Signifikansi Simultan (Uji Statistik} F)

Berdasarkan Tabel Output Eviews diatas diperoleh nilai $\mathrm{F}$ hitung sebesar 30.55834 dengan probabilitas (Prob FStatistic) sebesar 0.000 . Oleh karena probabilitas jauh lebih kecil dari 0.05, maka dapat disimpulkan bahwa kedua variabel independen secara simultan berpengaruh terhadap kinerja karyawan.

\section{c. Uji Signifikansi Parameter Individual (Uji Statistik t)}

Kedua variabel independen yang dimasukkan ke dalam model ternyata semua adalah signifikan, hal ini terlihat dari nilai probabilitas signifikansi keduanya dibawah 0.05. Uji $t$ digunakan untuk mengetahui apakah variabel independen secara parsial berpengaruh terhadap variabel dependen. Kriteria pengambilan keputusan untuk uji statistik $t$, yaitu apabila $\mathrm{t}$ hitung $>\mathrm{t}$ tabel atau sig $<\alpha=5 \%$, makah $\mathrm{H} 1$ diterima atau apabila $\mathrm{t}$ hitung, $\mathrm{t}$ tabel atau sig $>\alpha=5 \%$, maka H1 tidak dapat diterima. Berdasarkan hasil perhitungan statistik seperti pada Tabel 3.10, maka diperoleh persamaan regresi linear berganda sebagai berikut:

$$
Z=16,461+0,321 X+0,430 Y
$$

1. Konstanta

Berdasarkan Tabel 3.10 dan persamaan tersebut dapat diketahui bahwa konstanta $(\alpha)$ mempunyai koefisien regresi sebesar 16,461 artinya jika variabel adversity quotient $(\mathrm{X})$ dan motivasi kerja (Y) dianggap nol, maka adanya kenaikan kinerja sebesar $164,46 \%$ pada pengemudi taksi konvensional di kota Medan.

\section{Adversity Quotient}

Variabel adversity quotient (AQ) memiliki koefisien regresi sebesar 0,321 , artinya setiap kenaikan variabel $A Q$ sebesar $1 \%$,maka akan terjadi peningkatan kinerja sebesar 32,1\% dengan asumsi variabel lain dianggap konstan. Signifikansi variabel AQ sebesar $0,0002<\alpha=5 \%$. Maka secara parsial AQ berpengaruh signifikan terhadap kinerja pengemudi taksi konvensional di Kota Medan.

\section{Motivasi Kerja}

Variabel independen kedua adalah motivasi kerja yang mempunyai koefisien regresi sebesar 0.430 artinya setiap kenaikan variabel stres kerja sebesar $1 \%$ maka akan terjadi kenaikan variabel motivasi kerja sebesar 43,0\% dengan asumsi variabel lain dianggap konstan. Signifikansi variabel motivasi kerja sebesar 0,0142 < $\alpha=5 \%$. Maka secara parsial motivasi kerja berpengaruh signifikan terhadap kinerja pengemudi taksi konvensional di Kota Medan

3. Hasil Analisis Jalur (PATH Analysis)

Analisis jalur (PATH Analysis) dalam penelitian ini dapat digambarkan seperti pada gambar berikut ini:

\section{Gambar 2. Model Jalur Penelitian}

\section{Variabel Independen Variabel Intervening Variabel Dependen}

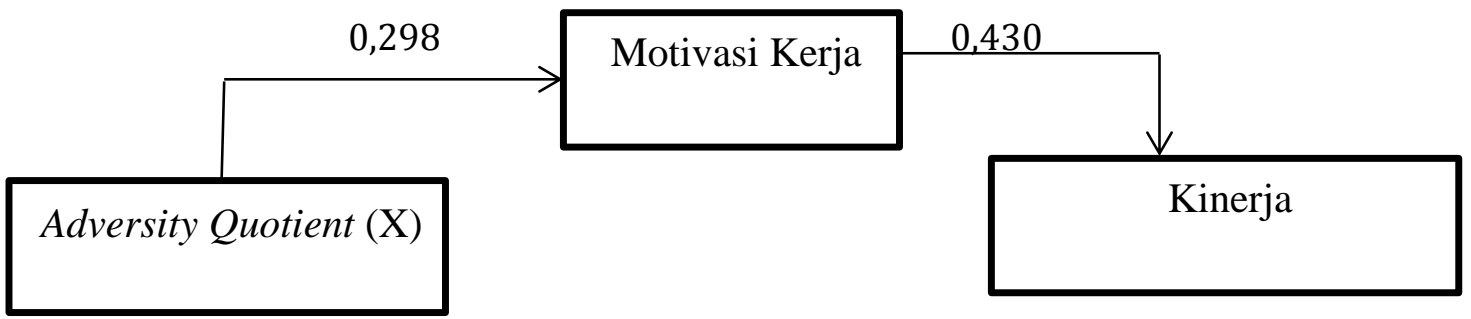


Pengaruh langsung, tidak langsung dan pengaruh total dapat dilihat pada Tabel 3.11 berikut ini:

Tabel 3.11 Pengaruh Langsung,Tidak Langsung, Total

\begin{tabular}{|l|c|c|c|}
\hline Keterangan & \multicolumn{1}{|c|}{ Pengaruh } & \\
\cline { 2 - 4 } & Langsung & $\begin{array}{c}\text { Tidak } \\
\text { Langsung }\end{array}$ & Total \\
\hline X terhadap Y (p1) & 0.298 & & \\
\hline Y terhadap Z (p2) & 0.430 & & \\
\hline Z terhadap Z (p3) & 0.321 & 0.095658 & 0.525658 \\
\hline
\end{tabular}

Berdasarkan perhitungan seperti 3.11, perhitungan pengaruh tidak langsung diperoleh dari perkalian koefisien perngaruh langsung adversity quotient terhadap motivasi kerja , dengan pengaruh motivasi kerja terhadap kinerja $(0,298 \times 0,321)=0,166935$. Pengaruh total diperoleh dengan menjumlahkan pengaruh langsung dan tidak langsung.

Menurut Ghozali (2013), bahwa uji Path analysis dapat dilakukan untuk menguji signifikansi pengaruh tidak langsung, maka kita perlu menghitung nilai $t$ dari koefisien uji Sobel persamaan $\alpha \beta$.

Pengaruh adversity quotient terhadap kinerja pengemudi taksi konvensional di Kota Medan melalui motivasi kerja sebagai variabel intervening.

Standard error dari koefisien indirect effect (Sp1p3) berikut ini.

Sp1p3 $=\sqrt{\mathrm{p}^{2} \mathrm{Sp} 1^{2}+\mathrm{p} 1^{2} \mathrm{Sp} 3^{2}+\mathrm{Sp}^{2} \mathrm{Sp} 3^{2}}$

Sp1p3 $=\sqrt{\left(0,430^{2}\right)(0.187965)^{2}+(0,298)^{2}(0.153096)^{2}+(0.187965)^{2}(0.153096)^{2}}$

Sp1p3 $=\sqrt{0,00653+0,1122+0,0587}$

Sp1p3 $=\sqrt{0,17743}$

Sp1p3 $=0,421$

Berdasarkan hasil Sp1p3 ini dapat dihitung nilai $t$ statistik uji Sobel pengaruh mediasi dengan rumus berikut ini:

$\mathrm{t}=\mathrm{p} 1 \mathrm{p} 3=0.095658=0,2272$

$$
\text { S̄1p3 } \quad \overline{0,421}
$$

Oleh karena nilai t hitung uji Sobel $=0,2271$ lebih kecil dari y tabel $=1,96$ dengan tingkat signifikansi 5\%, maka dapat disimpulkan bahwa motivasi kerja bukan merupakan variabel intervening antara pengaruh adversity quotient terhadap kinerja pengemudi taksi konvensional di Kota Medan, dengan

\section{KESIMPULAN}

Dari hasil analisis data dan pembahasan yang telah dilakukan dalam penelitian ini serta sesuai dengan tujuan penelitian, maka dapat disimpulkan bahwa Adversity quotient berpengaruh positif dan signifikan terhadap kinerja pegawai, Adversity quotient berpengaruh positif dan signifikan terhadap motivasi kerja, Motivasi kerja berpengaruh positif dan signifikan terhadap kinerja, dan Motivasi kerja bukan sebagai mediasi yang sempurna antara adversity quotient dan kinerja pegawai

\section{DAFTAR PUSTAKA}

A, A, R. Effects of Job Stress on Employees Job Performance A Study on Banking Sector of Pakistan. IOSR Journal of Business and Management (IOSRJBM) e-ISSN: 2278-487X, p-ISSN: 
2319-7668. Volume 11, Issue 6 (Jul. Aug. 2013), PP 61

A, A.M. 2013. Organizational Corporate Culture on Employee Performance. International Review of Management and Business Research.Vol. 2 Issue1

E. 2011. Metode Peneltian. USU Press. Medan.

G, I. 2016. Aplikasi Analisis Multivariate dengan Program SPSS. UNDIP. Semarang.

M. 2009. Sumber Daya Manusia Perusahaan. Bandung : Penerbit Rosdakarya.

M, R, J.H.J.2006. Manajemen Sumber Daya Manusia.Salemba Empat: Jakarta.

M.I, L.G. and A.H. A. Effects of Workplace Stress on Employee Performance in the County Governments in Kenya: A Case Study of Kilifi County Government. International Journal of Scientific and Research Publications ISSN 22503153,

M. 2009. Pengukuran Kinerja Berbasis Kompetensi . Bogor : GhaliaIndonesia
P, Er. S, Dr. Navjot Kaur. ADVERSITY QUOTIENT: A New Paradigm in Management to Explore. The International Journal's Research Journal of Social Science and Management ISSN 2251-1571 Volume:02 Number: 07, November 2012

S, C-Y. The Relative Study of Gender Roles, and Job Stress and Adversity Quotient. The Journal of Global Business Management Volume $10 *$ Number 1 * April 2014 issue.

S,P,G.2007.Adversity Quotient @Work. Batam: Interaksara

W, S.K. Job stress and its impact on employee motivation: a study of a select commercial bank, International Journal of Business and Management Invention ISSN (Online): 2319 8028, ISSN (Print): 2319 - 801X Volume 2 Issue 3 || March. 2013\| PP.13-18 . 